\title{
Protein domains and architectural innovation in plant-associated Proteobacteria
}

\author{
David J Studholme*1, J Allan Downie ${ }^{2}$ and Gail M Preston ${ }^{3}$
} Address: ${ }^{1}$ The Sainsbury Laboratory, Norwich, NR4 7UH, UK, ${ }^{2}$ Department of Molecular Microbiology, John Innes Centre, Norwich, NR4 7UH,
UK and ${ }^{3}$ Department of Plant Sciences, University of Oxford, Oxford, OX1 3RB, UK

Email: David J Studholme* - david.studholme@sainsbury-laboratory.ac.uk; J Allan Downie - allan.downie@bbsrc.ac.uk; Gail M Preston - gail.preston@plant-sciences.oxford.ac.uk

* Corresponding author

Published: 16 February 2005

BMC Genomics 2005, 6:17 doi:10.1186/147|-2164-6-17
Received: 18 August 2004

Accepted: 16 February 2005

This article is available from: http://www.biomedcentral.com/I47/-2/64/6/17

(c) 2005 Studholme et al; licensee BioMed Central Ltd.

This is an Open Access article distributed under the terms of the Creative Commons Attribution License (http://creativecommons.org/licenses/by/2.0), which permits unrestricted use, distribution, and reproduction in any medium, provided the original work is properly cited.

\begin{abstract}
Background: Evolution of new complex biological behaviour tends to arise by novel combinations of existing building blocks. The functional and evolutionary building blocks of the proteome are protein domains, the function of a protein being dependent on its constituent domains. We clustered completely-sequenced proteomes of prokaryotes on the basis of their protein domain content, as defined by Pfam (release 16.0). This revealed that, although there was a correlation between phylogeny and domain content, other factors also have an influence. This observation motivated an investigation of the relationship between an organism's lifestyle and the complement of domains and domain architectures found within its proteome.
\end{abstract}

Results: We took a census of all protein domains and domain combinations (architectures) encoded in the completely-sequenced proteobacterial genomes. Nine protein domain families were identified that are found in phylogenetically disparate plant-associated bacteria but are absent from non-plant-associated bacteria. Most of these are known to play a role in the plant-associated lifestyle, but they also included domain of unknown function DUFI427, which is found in plant symbionts and pathogens of the alpha-, beta- and gamma-Proteobacteria, but not known in any other organism. Further, several domains were identified as being restricted to phytobacteria and Eukaryotes. One example is the RolB/RolC glucosidase family, which is found only in Agrobacterium species and in plants. We identified the $0.5 \%$ of Pfam protein domain families that were most significantly over-represented in the plant-associated Proteobacteria with respect to the background frequencies in the whole set of available proteobacterial proteomes. These included guanylate cyclase, domains implicated in aromatic catabolism, cellulase and several domains of unknown function.

We identified 459 unique domain architectures found in phylogenetically diverse plant pathogens and symbionts that were absent from non-pathogenic and non-symbiotic relatives. The vast majority of these were restricted to a single species or several closely related species and so their distributions could be better explained by phylogeny than by lifestyle. However, several architectures were found in two or more very distantly related phytobacteria but absent from nonplant-associated bacteria. Many of the proteins with these unique architectures are predicted to be secreted. 
In Pseudomonas syringae pathovar tomato, those genes encoding genes with novel domain architectures tended to have atypical GC contents and were adjacent to insertion sequence elements and phage-like sequences, suggesting acquisition by horizontal transfer.

Conclusions: By identifying domains and architectures unique to plant pathogens and symbionts, we highlighted candidate proteins for involvement in plant-associated bacterial lifestyles. Given that characterisation of novel gene products in vivo and in vitro is time-consuming and expensive, this computational approach may be useful for reducing experimental search space. Furthermore we discuss the biological significance of novel proteins highlighted by this study in the context of plantassociated lifestyles.

\section{Background}

The Proteobacteria comprise a phylum of Gram-negative bacteria that includes an extraordinary diversity of lifestyles, ecology and metabolism. At one end of a spectrum are free-living organisms such as Pseudomonas aeruginosa, which has a relatively large genome that encodes enormous regulatory and metabolic flexibility, allowing it to colonise diverse niches. At the other extreme are highly specialised intracellular symbionts (Buchnera species, Rickettsia species), whose small genomes have undergone reductive evolution and which lack many common metabolic and regulatory features. With the availability of complete genome sequences for many model plant-associated bacteria, we are particularly interested in how genome analyses can be used to gain insights into the mechanisms and evolution of associations between bacteria and plants.

There are complete annotated genome sequences available for several phylogenetically diverse proteobacterial plant pathogens and symbionts, along with many of their non-pathogenic and non-symbiotic relatives. For example, among the alpha-Proteobacteria, complete genome sequences are available for the phytopathogen Agrobacterium tumefaciens [1-3], the nitrogen-fixing symbionts Bradyrhizobium japonicum [4], Mesorhizobium loti [5] and Sinorhizobium meliloti $[6,7]$, the non-pathogenic free-living Caulobacter crescentus [8], and the animal pathogenic Rickettsia species [9-11]. Ralstonia solanacearum [12] is the sole completely sequenced plant pathogen amongst the betaProteobacteria, a division that also includes animal pathogens in the genera Neisseria $[13,14]$ and Bordetella [15] and the free-living chemolithoautotroph Nitrosomonas europaea [16] whose genomes have been sequenced. Among the available complete genome sequences for the gamma-Proteobacteria are those of the plant pathogens Xylella fastidiosa [17,18], Xanthomonas campestris [19], Xanthomonas axonopodis [19] and Pseudomonas syringae pathovar tomato [20] as well as $P$. aeruginosa [21], which is an occasional pathogen of plants as well as animals.

Each of these three divisions of the Proteobacteria contains a wide variety of different lifestyles, so it is logical to assume that bacteria-plant interactions have evolved independently in multiple separate Proteobacterial lineages. Ultimately the differences between these lifestyles are determined by the organisms' genes acting through their expressed proteins and RNAs. Given the abundance of complete genome sequence data now available, a high priority is to understand which features of an organism's proteome determine its lifestyle, and the evolutionary processes underlying environmental adaptation and evolution of novel traits. Two main sources have been proposed for the evolution and acquisition of novel traits by bacteria: (i) duplication, mutation and recombination of existing genes within a single lineage, and (ii) lateral gene transfer between lineages. A combination of both bioinformatic and experimental studies are needed to determine the relative importance of these two processes in the evolution of plant-associated lifestyles in bacteria.

Evolution of new complex biological behaviours tends to arise (but not exclusively) by novel combinations of existing building blocks. The functional and evolutionary building blocks or units of the proteome are protein domains. Protein domains can be classified into families; examples of widely used classification schemes are those of Pfam [23] and SMART [24]. We hypothesised that systematic identification of proteins having domain architectures that are exclusive to plant-associated bacteria would identify good candidates for proteins with specific involvement in plant-microbial interactions, or in a plantassociated lifestyle, and would also generate insight into the distribution and evolution of novel traits in plantassociated bacteria.

\section{Results and discussion Hierarchical clustering of completely-sequenced prokaryotic proteomes}

To gain an overview of the similarities and differences between their protein domain content, we classified representative prokaryotes into hierarchical clusters based on their complement of protein domain families described. For each proteome we generated a 7,677 binary state element vector where each element represented the presence or absence of one of the 7,677 Pfam protein domain 


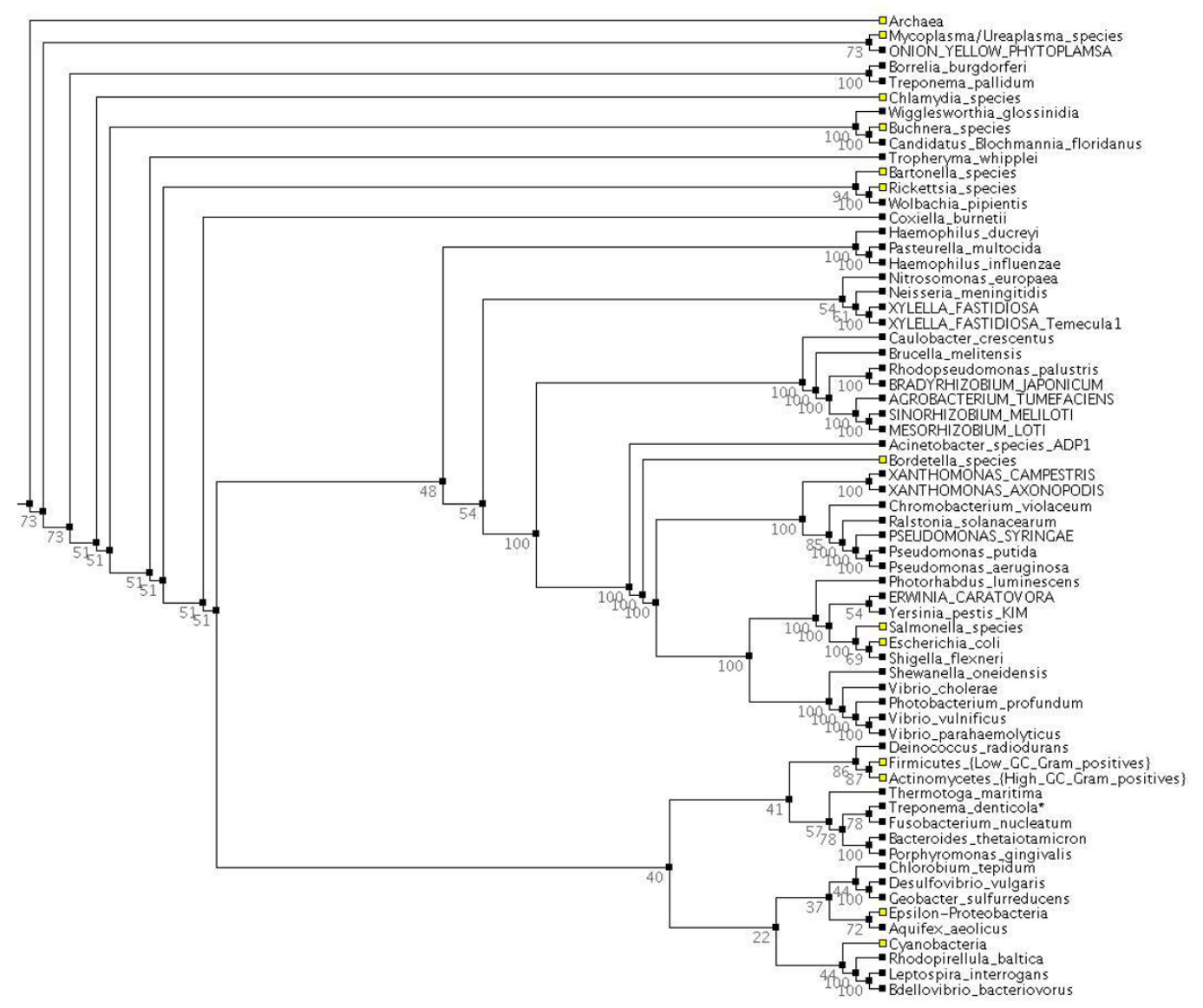

Figure I

Clustering of complete prokaryotic proteomes based on their protein domain content. 100 jacknife trials were performed, each leaving out a random $10 \%$ of the data.

families. Pairwise distances were calculated for each pair of proteomes based on the level of similarity between the pair of vectors, and tree was built by neighbour-joining (see Methods for more details). One hundred trees were built, each time leaving out $10 \%$ of the vector elements, selected at random. The tree shown in Figure 1 represents the consensus of these 100 jacknife trials.

The tree in Figure 1 illustrates the similarities and differences between prokaryotes with respect to their repertoire of recognisable protein domain families. There is clearly a correlation between domain complement and phylogeny; for example, the Archaea form a distinct cluster that is clearly separated from the Bacteria. Furthermore, within the Bacteria, the Cyanobacteria, Gram-positive Bacteria, chlamydias and mycoplasmas each fall into distinct clusters. However, there are some striking discrepancies between the protein domain-based clustering and phylogenetic classification. For example, the oral pathogen Treponema denticola (marked with an asterisk in Figure 1) clusters with the dental bacterium Fusobacterium nucleatum rather than with its fellow spirochetes T. pallidum and Borrelia burgdorferi.

It is notable that the Proteobacteria do not form a single distinct cluster in the protein-domain based classification in Figure 1. The cluster that contains the gamma-proteobacterial Pseudomonas and Xanthomonas species also contains the beta-Proteobacteria $R$. solanacearum and Chromobacterium violaceum. This probably reflects that these organisms have relatively large genomes and therefore share in common some common protein domains that are not encoded in smaller more streamlined genomes. Conversely X. fastidiosa, which has a relatively 
small genome, falls into a cluster with Neisseria meningitidis.

Interestingly, the plant pathogen E. caratovora fell into a cluster with Yersinia pestis, Salmonella species and E. coli, which are animal pathogens and commensals. This indicates that despite differing lifestyles, these species have diverged relatively little with respect to loss and gain of protein domain families.

Overall, the results of clustering bacterial proteomes on the basis of their domain content suggested that in addition to phylogeny, an organism's domain repertoire may reflect other factors, possibly including genome size and lifestyle. These preliminary observations led us to investigate whether it is possible to identify any particular domains or domain architectures that may be characteristic of a plant-associated lifestyle.

\section{Protein domain families restricted to plant-associated bacteria}

We queried the Pfam 16.0 database to determine the species distribution of each of the 7,677 domain families. Of these, 85 were found in at least one of the completely sequenced plant associated bacteria but absent from all other completely sequenced bacteria. Most of these domain families are restricted to a single species or group of very closely related organisms. For example, domain of unknown function DUF1484 (Pfam:PF07363) appears to be restricted to Ralstonia solanacearum, whilst DUF1520 (Pfam:PF07480) is restricted to Bradyrhizobium japonicum and Sinorhizobium meliloti. Although it is possible that these species-specific domain families are involved in pathogenesis or symbiosis it is equally likely that they have some unrelated function. However, several domains are potentially interesting from the point of view of plantmicrobe interactions either because they are found in phylogenetically disparate species of phytobacteria or because they are also found in eukaryotes. Table 1 lists the domain families that are found in plant-associated members of more than one subdivision of the Proteobacteria, but are not found in any non-plant-associated bacteria. Several of these are already implicated in host-plant interactions. For example, proteins belonging to the NolX family (Pfam:PF05819) include HrpF from the gamma-proteobacterium X. campestris and NolX from the alpha-proteobacterium Rhizobium fredii and Rhizobium species NGR234. In these rhizobia, NolX (also referred to as NopX) has been shown to play a role in nodulation specificity and is exclusively expressed during the early stages of interactions with plants $[25,26]$. NolX is thought to facilitate protein secretion into the plant host via a type III secretion system [27], and a similar role has been postulated for X. campestris HrpF [28]. The importance of members of the NolX family in microbe-plant interactions is reinforced by our observation that they are also found in several other plant-associated alpha- and gamma-Proteobacteria as well as in the phytopathogenic beta-proteobacterium R. solanacearum (see Table 1), but are not found in any other completely sequenced genomes. Similarly, the Avirulence domain (Pfam:PF03377) is restricted to the phytopathogens $R$. solanacearum and Xanthomonas species [29].

A further protein family limited to plant-associated bacteria is characterised by the ice nucleation repeat (Pfam:PF00818)and is found in proteins that may have a role in frost damage to host plants. It remains to be seen whether the remaining two domain families (DUF811 and DUF1427) are involved in the plant-associated lifestyle. DUF1427 (Pfam:PF07235) is restricted to several plant-associated alpha-Proteobacteria, the beta-proteobacterium $R$. solanacearum and the gamma-Proteobacteria $P$. aeruginosa and $X$. campestris (Table 1). Although their functions are unknown, proteins containing DUF1427 are thus candidates for involvement in interactions with plants or may at least have a role in plant-associated lifestyles. Several of these proteins have predicted signal peptide sequences and / or predicted transmembrane regions, suggesting an extracytoplasmic location. This may be indicative of a role in extracellular interactions with plants or with other components of the environment. Table 2 lists the 13 protein domain families that appear to be restricted to plant-associated bacteria and to eukaryotes and/or Archaea. Interestingly, this highlights at least one example of a protein domain that has probably been recruited into plant-associated bacteria from a plant host. Proteins containing a RolB/RolC-like domain (Pfam:PF02027) are found to be restricted to plant-associated alpha-Proteobacteria and to plants of the genus Nicotiana (see Table 2 and Figure 2). The activity of these proteins in plants may lead to an increase in intracellular auxin activity caused by the release of active auxins from inactive beta-glucosides [30,31]. The presence of many Agrobacterium-like proteins in Rhizobium (Agrobacterium) vitis reflects another key feature of the biology of these plant-associated bacteria, the fact that many of the genes involved directly in Agrobacterium and Rhizobium- plant interactions are encoded on large plasmids that facilitate lateral gene transfer of complex and novel traits between bacteria. Rhizobium (Agrobacterium) vitis is not a symbiont, but rather causes a tumorigenic disease of grapevine through the action of a number of $A$. tumefaciens-like genes [32].

\section{Protein domain families that are over-represented in plant-associated bacteria}

Bacterial physiology and behaviour is determined not only by the presence or absence of particular proteins but also by numbers of representatives of protein families. For 
Table I: Pfam protein domain families found in phylogentically disparate plant-associated bacteria and not found in non-plant associated bacteria.

\begin{tabular}{|c|c|}
\hline Pfam domain family & Species distribution \\
\hline 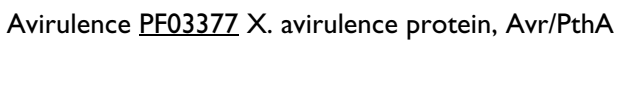 & $\begin{array}{l}\text { R. solanacearum; } X \text {. axonopodis (pv. citri); } X . \text { campestris ( } p v . \text { citri); } X \text {. } \\
\text { campestris (pv. vesicatoria); } X \text {. campestris; } X . \text { manihotis; } X . \text { oryzae ( } p v \text {. } \\
\text { oryzae); } X \text {. oryzae; }\end{array}$ \\
\hline DspF PF06704 DspF/AvrF protein & $\begin{array}{l}\text { Erwinia amylovora; E. carotovora subsp. atroseptica SCRII043; Erwinia } \\
\text { pyrifoliae; Erwinia stewartii; Pantoea agglomerans (pv. gypsophilae) (Erwinia } \\
\text { herbicola); Pectobacterium atrosepticum; P. syringae (pv. tomato); P. syringae; }\end{array}$ \\
\hline DUFI427 PF07235 Domain of unknown function & $\begin{array}{l}\text { A. tumefaciens (strain C58 / ATCC 33970); B. japonicum; P. aeruginosa; } R \text {. } \\
\text { solanacearum; Rhizobium leguminosarum (biovar trifolii); Rhizobium meliloti } \\
\text { (Sinorhizobium meliloti); X. campestris (pv. campestris); }\end{array}$ \\
\hline DUF8I I PF05665 Domain of unknown function & $P$. aeruginosa; $R$. solanacearum; \\
\hline HrpE PF06188 HrpE protein & $\begin{array}{l}\text { Erwinia amylovora; E. carotovora subsp. atroseptica SCRII 043; Erwinia } \\
\text { chrysanthemi; Erwinia pyrifoliae; Erwinia stewartii; Pectobacterium } \\
\text { atrosepticum; Pectobacterium carotovorum (subsp. carotovorum) (E. } \\
\text { carotovora (subsp. carotovora)); P. fluorescens; } P \text {. syringae (pv. glycinea); } P \text {. } \\
\text { syringae (pv. phaseolicola); } P \text {. syringae (pv. savastanoi); P. syringae (pv. } \\
\text { syringae); } P \text {. syringae (pv. tabaci); P. syringae (pv. tomato); } P \text {. syringae; }\end{array}$ \\
\hline HrpF PF06266 HrpF protein & $\begin{array}{l}\text { Erwinia amylovora; E. carotovora subsp. atroseptica SCRII 043; Erwinia } \\
\text { chrysanthemi; Erwinia pyrifoliae; Erwinia stewartii; Pectobacterium } \\
\text { atrosepticum;Pectobacterium carotovorum (subsp. carotovorum) (E. carotovora } \\
\text { (subsp. carotovora)); P. syringae (pv. glycinea); P. syringae (pv. phaseolicola); P. } \\
\text { syringae (pv. savastanoi); P. syringae (pv. syringae); P. syringae (pv. tabaci); } P \text {. } \\
\text { syringae (pv. tomato); }\end{array}$ \\
\hline Ice_nucleation PF008I8 Ice nucleation protein repeat & $\begin{array}{l}\text { Bordetella phage BPP-I; Erwinia herbicola; Pantoea ananas (Erwinia } \\
\text { uredovora); P. fluorescens; } P \text {. syringae (pv. syringae); P. syringae; X. campestris } \\
\text { (pv. campestris); X. campestris (pv. translucens); }\end{array}$ \\
\hline NolX PF05819 NolX protein & $\begin{array}{l}\text { R. solanacearum; Rhizobium fredii (Sinorhizobium fredii); Mesorhizobium loti; } \\
\text { Rhizobium sp. (strain NGR234); X. axonopodis (pv. citri); X. axonopodis pv. } \\
\text { glycines; X. campestris (pv. campestris); X. campestris (pv. vesicatoria); X. } \\
\text { oryzae (pv. oryzae); }\end{array}$ \\
\hline VirK PF06903 VirK protein & $\begin{array}{l}\text { A. tumefaciens (strain C58 / ATCC 33970); A. tumefaciens; B. japonicum; P. } \\
\text { syringae (pv. tomato); R. solanacearum; Rhizobium sp. (strain NGR234); X. } \\
\text { axonopodis (pv.citri); X. campestris (pv. campestris); X. fastidiosa (strain } \\
\text { Temeculal / ATCC 700964); X. fastidiosa; }\end{array}$ \\
\hline
\end{tabular}

Table 2: Pfam protein domain families restricted to plant-associated bacteria and eukaryotes.

\begin{tabular}{|c|c|}
\hline Pfam domain family & Species distribution (not exhaustive) \\
\hline CBM_14 PF01607 Chitin binding Peritrophin-A domain & Ralstonia solanacearum; Metazoa; Fungi; Viruses \\
\hline CD225 PF04505 Interferon- induced transmembrane protein & Xanthomonas campestris (pv campestris); Metazoa; \\
\hline DUF726 PF05277 Protein of unknown function (DUF726) & Pseudomonas syringae (pv tomato); Metazoa; Plants; \\
\hline DUF763 PF05559 Protein of unknown function (DUF763) & $\begin{array}{l}\text { Mesorhizobium loti; Sinorhizobium meliloti; Xanthomonas axonopodis (pv. } \\
\text { citri); Xanthomonas campestris (pv. campestris); Archaea; }\end{array}$ \\
\hline GDAI_CD39 PF0II50 GDAI/CD39 (nucleoside phosphatase) family & Pseudomonas syringae (pv. Tomato); Plants; Fungi; Metazoa; \\
\hline Het-C PF07217 Heterokaryon incompatibility protein Het-C & Pseudomonas syringae (pv. tomato); Fungi; \\
\hline PAX PF00292 'Paired box' domain & Rhizobium etli; Mesorhizobium loti; Metazoa; \\
\hline PPR PF0I535 PPR repeat & Ralstonia solanacearum; Plants; Metazoa; Fungi; \\
\hline Rhamnogal_lyase PF06045 Rhamnogalacturonate lyase family & Erwinia carotovora subsp. atroseptica SCRII 043; Erwinia chrysanthemi; Plants; \\
\hline Ribosomal_60s PF00428 60s Acidic ribosomal protein & $\begin{array}{l}\text { Ralstonia solanacearum (Pseudomonas solanacearum); Plants; Metazoa; } \\
\text { Archaea; }\end{array}$ \\
\hline RolB_RolC PF02027 RolB/RolC glucosidase family & $\begin{array}{l}\text { Agrobacterium rhizogenes; Agrobacterium tumefaciens (strain Ach5), and } \\
\text { Agrobacterium tumefaciens (strain I 5955); Agrobacterium tumefaciens (strain } \\
\text { Ach5), and Agrobacterium tumefaciens; Agrobacterium tumefaciens (strain } \\
\text { Ach5); Agrobacterium tumefaciens (strain C58 / ATCC 33970); Agrobacterium } \\
\text { tumefaciens; Agrobacterium vitis (Rhizobium vitis); Plants; }\end{array}$ \\
\hline SBP56 PF05694 56 kDa selenium binding protein (SBP56) & Bradyrhizobium japonicum; ; Plants; Metazoa; Archaea; \\
\hline ST7 PF04I84 ST7 protein & Rhizobium loti (Mesorhizobium loti); Metazoa; \\
\hline
\end{tabular}




\begin{tabular}{ll} 
RolB_RolC Amino_oxidase & A.tumefaciens laaM (755 residues) \\
\hline RolB_RolC & Nicotiana glauca NgORF13 (195 residues) \\
RolB_RolC & A. tumefaciens Tiorf185 (186 residues)
\end{tabular}

Figure 2

Examples of proteins containing a RolB/RolC domain.

Table 3: Protein domain families over-represented in plant-associated proteobacteria.

\begin{tabular}{|c|c|c|c|c|}
\hline \multicolumn{2}{|l|}{ Domain family } & \multirow{2}{*}{$\begin{array}{l}\text { Expected number of } \\
\text { proteins }\end{array}$} & \multirow{2}{*}{$\begin{array}{l}\text { Observed number of } \\
\text { proteins }\end{array}$} & \multirow[t]{2}{*}{$P$} \\
\hline Pfam accesion & Pfam ID & & & \\
\hline PF002II & Guanylate_cyc & 33.39 & 70 & 2.17E-008 \\
\hline PF00296 & Bac_luciferase & 46.36 & 81 & $2.56 \mathrm{E}-006$ \\
\hline PF04828 & DUF636 & 36.58 & 65 & I.40E-005 \\
\hline PF04679 & DNA_ligase_A_C & 17.65 & 38 & I.76E-005 \\
\hline PF0I068 & DNA_ligase_A_M & 24.03 & 47 & $2.18 \mathrm{E}-005$ \\
\hline PF02738 & Ald_Xan_dh_C2 & 35.72 & 63 & $2.33 \mathrm{E}-005$ \\
\hline PF03758 & SMP-30 & 19.35 & 40 & $2.63 \mathrm{E}-005$ \\
\hline PF0I638 & DUF24 & 37 & 64 & $3.5 \mathrm{IE}-005$ \\
\hline PF0I757 & Acyl_transf_3 & 54.86 & 87 & $3.75 \mathrm{E}-005$ \\
\hline PF00067 & $\mathrm{p} 450$ & 24.24 & 46 & $5.3 \mathrm{IE}-005$ \\
\hline PF02746 & MR_MLE_N & 50.18 & 80 & $6.30 \mathrm{E}-005$ \\
\hline PF02894 & GFO_IDH_MocA_C & 66.35 & 100 & 6.97E-005 \\
\hline PF0I799 & Fer2_2 & 31.26 & 55 & 7.69E-005 \\
\hline PF06169 & DUF982 & 11.06 & 26 & $8.88 \mathrm{E}-005$ \\
\hline PF07536 & HWE_HK & 23.82 & 44 & I.35E-004 \\
\hline PF0I022 & HTH_5 & 68.47 & 101 & I.38E-004 \\
\hline PF03573 & OprD & 14.03 & 30 & I.4IE-004 \\
\hline PF00656 & Peptidase_Cl4 & 14.89 & 31 & I.73E-004 \\
\hline PF03459 & TOBE & 83.78 & 139 & $2.48 \mathrm{E}-004$ \\
\hline PF02627 & CMD & 51.89 & 79 & 2.75E-004 \\
\hline PF0II 88 & MR_MLE & 56.78 & 85 & 2.79E-004 \\
\hline PF07506 & $\operatorname{RepB}$ & 10.84 & 24 & $3.8 I \mathrm{E}-004$ \\
\hline PF0I26I & AP_endonuc_2 & 85.48 & 122 & 4.9IE-004 \\
\hline PF00I50 & Cellulase & 11.06 & 24 & 4.97E-004 \\
\hline PF0I 408 & GFO_IDH_MocA & 85.7 & 130 & $5.36 \mathrm{E}-004$ \\
\hline PF0094I & FAD_binding_5 & 21.05 & 38 & $5.58 \mathrm{E}-004$ \\
\hline PF0I3I5 & Ald_Xan_dh_C & 29.35 & 49 & $5.60 \mathrm{E}-004$ \\
\hline PF00353 & HemolysinCabind & 36.15 & 57 & $8.12 E-004$ \\
\hline PF06823 & DUFI236 & 8.93 & 20 & $9.64 \mathrm{E}-004$ \\
\hline
\end{tabular}


example, gene duplication events may lead to a lineagespecific expansion that results in novel orthologues that can take on novel functions different from that of the parent gene. Therefore we investigated whether any protein domain families were over-represented in the plantassociated proteobacteria with respect to the background distribution of domains in all Proteobacteria for which complete sequences were available. For each of the 7,677 Pfam domain families, we counted the numbers of proteins in which that domain family occurs in the complete proteomes of Erwinia carotovora, Pseudomonas syringae pathovar tomato, Ralstonia solanacearum, Sinorhizobium meliloti, Bradyrhizobium japonicum, Mesorhizobium loti, Agrobacterium tumefaciens (Washington strain and Dupont strain), Xanthomonas campestris pathovar campestris, Xanthomonas axonopodis pathovar citri, Xylella fastidiosa and Xylella fastidiosa (strain Temecula1). We then calculated a $\mathrm{P}$ value for the probability of observing at least this number of occurrences given the background frequency in the Proteobacteria and assuming a binomial distribution. The smaller the P value, the less likely that the observed frequency occurred by chance. In other words, the smaller the $\mathrm{P}$ value, the more over-represented is the domain family. The most over-represented domains are listed in Table 3.

The domain with the statistically most significant overrepresentation in the plant-associated bacteria was the guanylate cyclase domain (Pfam:PF00211). This domain was particularly abundant in $B$. japonicum (32 proteins) and S. meliloti (24 proteins). No other fully-sequenced proteobacterium encodes more than three, although the spirochaete Leptospira interrogans encodes 17 proteins matching PF00211). Cyclic-diGMP, the product of guanylate cyclase, is a secondary messenger that plays a role in cell-cell and cell-surface contact in several bacteria by regulating cellular adhesion genes [33]. Such interactions are very important in initiating bacterial infection of eukaryotic organisms and this may account in part for the high numbers of such domains in these plant-associated bacteria. Of particular interest is the observation that one response regulator from $C$. crescentus has been shown to become sequestered to the cell pole following phosphorylation [35]. This is coupled to the activation of the guanylate cyclase domain, suggesting that localised synthesis of this secondary message could induce local effects within specific regions of the bacterial cell.

Another domain with statistically significant over-representation in the plant-associated bacteria was the bacterial luciferase-like monooxygenase domain (Pfam:PF00296). This domain was particularly abundant in the plant-associated alpha-Proteobacteria with 15 proteins in Agrobacterium tumefaciens, 11 proteins in $B$. japonicum and 9 proteins in M. loti containing this domain. The related
alpha-Proteobacteria C. crescentus, B. melitensis, B. suis and Rhodopseudomonas palustris have 3, 2, 2 and 0 luciferase (PF00296) proteins respectively. Other species containing large numbers of luciferase-like proteins include Mycobacterium bovis (13 proteins) and M. tuberculosis (14 proteins).

Several domains of unknown function are amongst those most over-represented in the phytobacteria. For example, DUF636 is unusually abundant in the rhizobia with 16 representative proteins in B. japonicum and 14 and 13 in $M$. loti and $S$. meliloti respectively. Other prokaryotes encode between 0 and 5 DUF636 proteins, whilst Arabidopsis thaliana and Homo sapiens each encode one.

\section{Domain architectures}

The functionality of the proteome depends not only on the repertoire of protein domains but also on the interactions and cellular context of those domains. One important aspect of this context is the range of combinations of domains within a protein; that is the domain architecture of proteins.

We used the Pfam database to ascertain the domain architecture of every protein sequence from each bacterial species for which a complete annotated genome sequence was available. 3,774 distinct protein domain architectures were found in $R$. solanacearum, $P$. aeruginosa, E. carotovora (subspecies atroseptica), P. syringae (pathovar tomato), B. japonicum, S. meliloti, M. loti, A. tumefaciens, X. fastidiosa, X. campestris, X. axonopodis. 459 of the 3,774 domain architectures encoded in genomes of plant-associated bacteria were absent in all other bacteria for which complete genome sequences were available. These 459 architectures are listed in the supplementary data. However, many of these architectures were restricted to a single species or several closely related species and so were of limited interest for this study.

We were particularly interested to discover whether any domain architectures are related to plant-associated lifestyle rather than simply resulting from phylogeny. The 15 protein architectures illustrated in Table 4 were each found in plant-associated bacteria from at least two different divisions of the Proteobacteria and were not found in any other non-plant-associated organisms. For example, polypeptide sequences consisting of an N-terminal domain of unknown function DUF442 fused to a metallobeta-lactamase domain are restricted to A. tumefaciens, $M$. loti, S. meliloti, X. fastidiosa and X. fastidiosa.The metallobeta-lactamase domain (Pfam:PF00753) is common and widespread, being found in over 2000 different proteins from a wide range of organisms. However, only in these proteins from plant-associated bacteria is the metallobeta-lactamase domain fused to DUF442. This suggests 
Table 4: Domain architectures found in phytobacteria of two or more subdivisions of the Proteobacteria and not found in non-plantassociated bacteria.

\begin{tabular}{|c|c|c|}
\hline Domain architecture & Species distribution & Proteins \\
\hline DUF763 & $\begin{array}{l}\text { Aeropyrum pernix; Archaeoglobus fulgidus; } \\
\text { Bradyrhizobium japonicum; } \\
\text { Methanobacterium thermoautotrophicum; } \\
\text { Methanopyrus kandleri; Picrophilus torridus; } \\
\text { Pyrobaculum aerophilum; Pyrococcus abyssi; } \\
\text { Pyrococcus furiosus; Pyrococcus horikoshii; } \\
\text { M. loti; S. meliloti; Sulfolobus solfataricus; } \\
\text { Sulfolobus tokodaii; Thermoplasma } \\
\text { acidophilum; Thermoplasma volcanium; X. } \\
\text { axonopodis (pv. citri); X. campestris (pv. } \\
\text { campestris); }\end{array}$ & 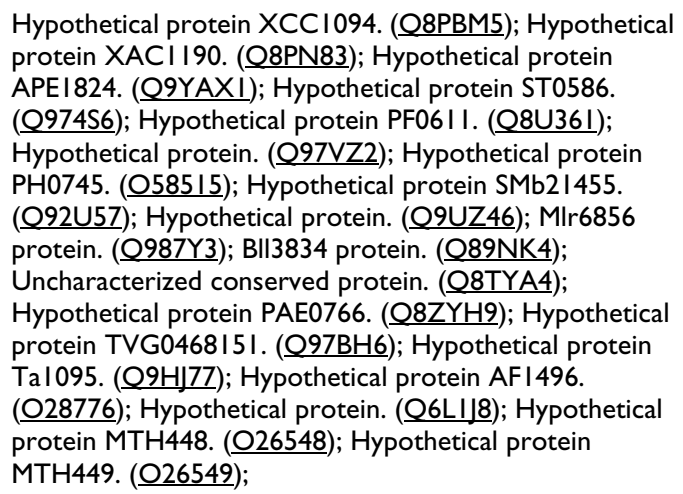 \\
\hline Virk & $\begin{array}{l}\text { A. tumefaciens (strain C58 / ATCC 33970); } \\
\text { A. tumefaciens; Bradyrhizobium japonicum; } \\
\text { P. syringae (pv. tomato); R. solanacearum; } \\
\text { Rhizobium sp. (strain NGR234); X. } \\
\text { axonopodis (pv. citri); X. campestris (pv. } \\
\text { campestris); X. fastidiosa (strain Temecula I } \\
\text { / ATCC 700964); X. fastidiosa; }\end{array}$ & 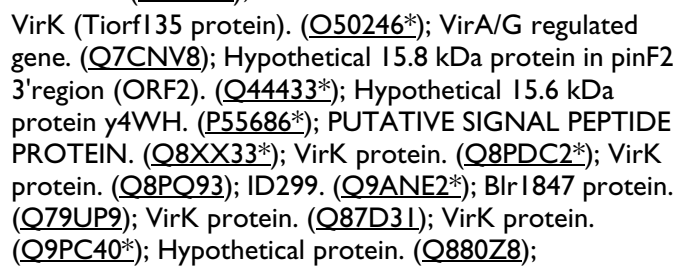 \\
\hline DUFI427 & $\begin{array}{l}\text { A. tumefaciens (strain C58 / ATCC 33970); } \\
\text { Bradyrhizobium japonicum; P. aeruginosa; R. } \\
\text { solanacearum; Rhizobium leguminosarum } \\
\text { (biovar trifolii); S. meliloti; X. campestris (pv. } \\
\text { campestris); }\end{array}$ & $\begin{array}{l}\text { Hypothetical protein XCC2052. (Q8P9|4); Bsl6958 } \\
\text { protein. (Q89EW2); Hypothetical protein. (Q93EB2); } \\
\text { HYPOTHETICAL TRANSMEMBRANE PROTEIN. } \\
\text { (Q8Y2U1*); AGR_L_1747p. (Q8U4X9*); Hypothetical } \\
\text { protein. (Q92Y85); Bsr4258 protein. (Q89MD5); } \\
\text { Hypothetical protein. (Q910E5*); }\end{array}$ \\
\hline DUFI486 & $\begin{array}{l}\text { A. tumefaciens (strain C58 / ATCC 33970); } \\
\text { Neurospora crassa; } P \text {. aeruginosa; } P \text {. } \\
\text { syringae (pv. tomato); R. solanacearum; M. } \\
\text { loti; S. meliloti; }\end{array}$ & $\begin{array}{l}\text { Hypothetical protein. (Q7SFH5); Hypothetical protein } \\
\text { Atu3018. (Q8UBJ8); Hypothetical protein. (Q92YLI); } \\
\text { Mlr2224 protein. (Q98IWI); Hypothetical protein. } \\
\text { (Q913U3); Hypothetical protein. (Q9JP27); } \\
\text { AGR_L_357Ip. (Q7CRD4); Hypothetical protein } \\
\text { RSc0819. (Q8Y I7I); }\end{array}$ \\
\hline RepB & $\begin{array}{l}\text { A. tumefaciens (strain C58 / ATCC 33970); } \\
\text { P. syringae (pv. tomato); M. loti; S. meliloti; }\end{array}$ & $\begin{array}{l}\text { Msr9757 protein. (Q98P91); MII8I I5 protein. (Q983Y2); } \\
\text { Hypothetical protein. (Q88BH6); Hypothetical protein } \\
\text { Atu5040. (Q8UKR0); AGR_PAT_52p. (Q7D423); } \\
\text { Hypothetical protein. (Q92XS2); Hypothetical protein. } \\
\text { (Q930E6); Hypothetical protein. (Q930E5); }\end{array}$ \\
\hline DUF442 Lactamase_B & $\begin{array}{l}\text { A. tumefaciens (strain C58 / ATCC 33970); } \\
\text { M. loti; S. meliloti; X.fastidiosa (strain } \\
\text { Temecula I / ATCC 700964); X. fastidiosa; }\end{array}$ & $\begin{array}{l}\text { Metallo-beta-lactamase superfamily protein. (Q8UAA9); } \\
\text { Hypothetical protein. (Q92ZB8); AGR_L_2726p. } \\
\text { (Q7CS)2); Hypothetical protein. (Q87AD6); Mlr2I58 } \\
\text { protein. (Q98JI2); Hypothetical protein. (Q9PFB0); }\end{array}$ \\
\hline GAF Phytochrome & $\begin{array}{l}\text { Bradyrhizobium sp. ORS278; X. axonopodis } \\
\text { (pv. citri); }\end{array}$ & $\begin{array}{l}\text { Phytochrome-like protein. (Q8PEQ2); } \\
\text { Bacteriophytochrome. (Q8VUB6); }\end{array}$ \\
\hline Glyco_hydro_6 CBM_2 & $\begin{array}{l}\text { Microbispora bispora; Micromonospora } \\
\text { cellulolyticum; } R \text {. solanacearum; } \\
\text { Thermomonospora fusca; X. fastidiosa } \\
\text { (strain Temeculal / ATCC 700964); X. } \\
\text { fastidiosa; }\end{array}$ & 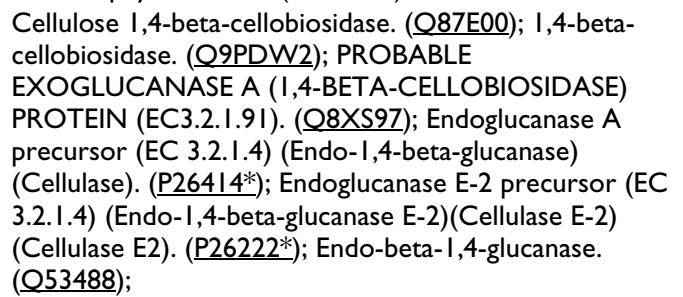 \\
\hline DUF8II & P. aeruginosa; $R$. solanacearum; & $\begin{array}{l}\text { Hypothetical protein. (Q916E4*); Hypothetical protein. } \\
\text { (Q916E5*); Hypothetical protein RSc3082. (Q8XUVI); }\end{array}$ \\
\hline $\begin{array}{l}\text { Condensation Condensation AMP- } \\
\text { binding PP-binding Condensation AMP- } \\
\text { binding PP- binding Condensation AMP- }\end{array}$ & P. syringae (pv. tomato); R. solanacearum; & $\begin{array}{l}\text { Probable peptide synthesis protein. ( }(\mathrm{Q} 8 \mathrm{XS} 39) \text {; Non- } \\
\text { ribosomal peptide synthetase, terminal component. } \\
\text { (Q88|Q3); }\end{array}$ \\
\hline
\end{tabular}

binding PP- binding Condensation AMPbinding PP- binding Condensation AMPbinding PP-

binding Thioesterase Thioesterase 
Table 4: Domain architectures found in phytobacteria of two or more subdivisions of the Proteobacteria and not found in non-plantassociated bacteria. (Continued)

\begin{tabular}{|c|c|c|}
\hline NolX & $\begin{array}{l}\text { R. solanacearum; Rhizobium fredii } \\
\text { (Sinorhizobium fredii); M. loti; Rhizobium sp. } \\
\text { (strain NGR234); X. axonopodis (pv. citri); } \\
\text { X. axonopodis pv. glycines; X. campestris } \\
\text { (pv. campestris); X. campestris (pv. } \\
\text { vesicatoria); X. oryzae (pv. oryzae); }\end{array}$ & 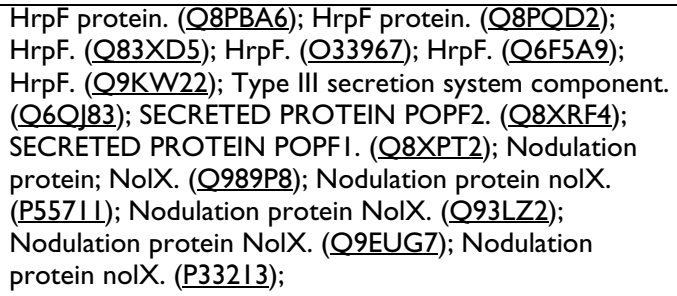 \\
\hline DUF802 DUF802 & R. solanacearum; X. axonopodis (pv. citri); & $\begin{array}{l}\text { Hypothetical protein XAC3753. (Q8PG64*); Probable } \\
\text { transmembrane protein (Q8XQ05*); }\end{array}$ \\
\hline Avirulence Avirulence & $\begin{array}{l}\text { R. solanacearum; } X \text {. axonopodis ( } p v \text {. citri); } \\
X . \text { campestris ( } p v \text {. citri); X. campestris ( } p v \text {. } \\
\text { vesicatoria); X. campestris; X. oryzae ( } p v \text {. } \\
\text { oryzae); X. oryzae; }\end{array}$ & 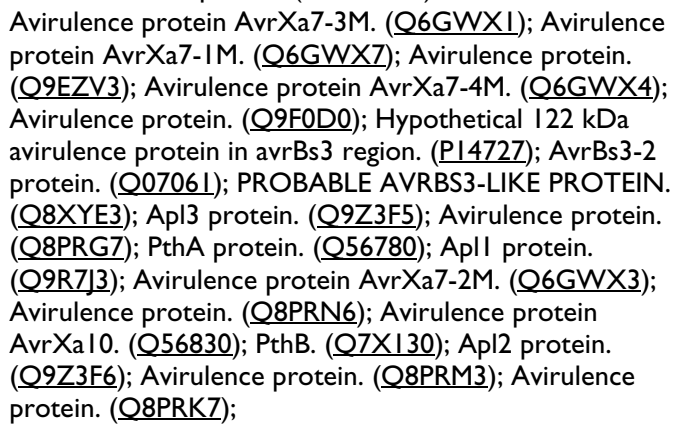 \\
\hline RgpF-RgpF & $\begin{array}{l}\text { M. loti; Rhizobium sp. (strain NGR234); X. } \\
\text { axonopodis (pv. citri); X. campestris (pv. } \\
\text { campestris); }\end{array}$ & 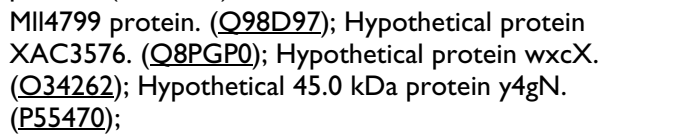 \\
\hline TPR_2 TPR_I Sulfotransfer_I & $\begin{array}{l}\text { M. loti; X. axonopodis (pv. citri); uncultured } \\
\text { bacterium 560; }\end{array}$ & 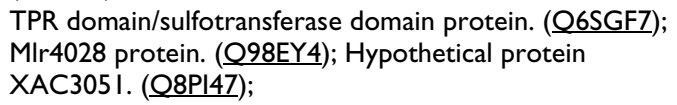 \\
\hline
\end{tabular}

that the catalytic domain may have been recruited to some new function connected to a plant-associated lifestyle in these bacteria.

One regulatory domain found in large numbers in Pseudomonas genome is the PAS domain (Pfam PF00989) [36], which is present in 25 ORFs in $P$. aeruginosa PAO1 and 30 ORFs in P. syringae pathovar tomato. The average number of PAS-containing ORFs in complete proteobacterial genomes is about 10. Although PAS domains are only found in a limited subset of bacterial regulators, they are at the forefront of molecular innovation with 9 of the novel architectures identified in $P$. aeruginosa, and 5 of those in $P$. syringae pathovar tomato containing PAS domains (see supplementary data for more details). Xanthomonas genomes also encode a large number of PAScontaining polypeptides, (18 and 21 in X. axonopodis and $\mathrm{X}$. campestris respectively). However, each X. fastidiosa encodes only one: PhoR, a regulator generally associated with responses to phosphate limitation. Ten novel PAS architectures are present in each Xanthomonas genome, of which 7 are common and 3 are unique to each strain (some of which are illustrated in Figure 3). PAS domains, which are involved in sensing light, oxygen and other environmental factors, have particular importance in helping bacteria to adapt to a changing environment, an ability of little value to $X$. fastidios $a$ in its restricted and relatively constant niches.

One intriguing signal transduction domain identified in unique domain architectures from both $P$. syringae and Xanthomonas was a phytochrome domain (Pfam:PF00360) (Figure 4). This domain enables lightmediated signal transduction in plants and bacteria, through binding a light-sensitive chromophore $[37,38]$. Phytochrome-containing proteins are used to detect light, and to discriminate between different wavelengths of light. Phytochromes are used for shade avoidance by plants, and to detect depth in soil or water or other conditions where light is attenuated. The short list of bacteria that contain phytochromes includes photosynthetic species (e.g. Rhodospirillum centenum, Anabaena species strain PCC7120 and Synechocystis species strain PCC6803) as well as plant associated bacteria (e.g. R. leguminosarum, A. tumefaciens) and soil bacteria (e.g. P. putida) $[38,39]$. An unusual photosynthetic strain, Bradyrhizobium species ORS278 uses phytochrome to regulate the photosynthesis gene cluster and a similar induction was seen with Rhodopseudomonas pallustris but not with several other photosynthetic bacteria [40]. It is not known why phytochrome 


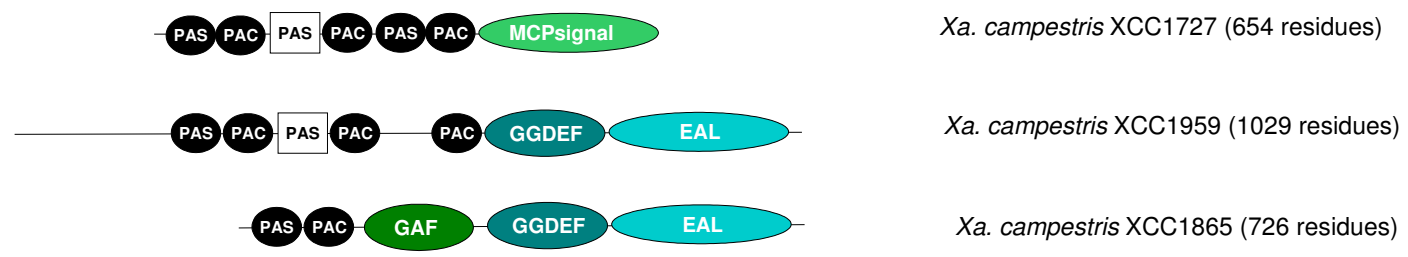

GAF PA PAC PAS PAC PAS PAC PAS PAC GGDEF Xa. campestris XCC3523 (865 residues)

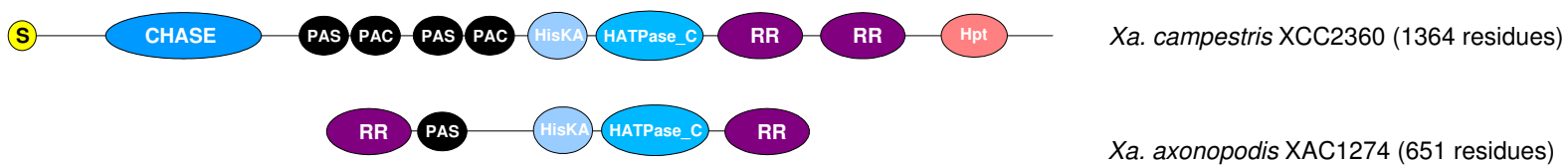

Figure 3

Examples of proteins containing phytochrome domains.

PAS RhytoChr Rhodospirillum centenum Q9X2W8 (884 residues)

Figure 4

Examples of proteins containing phytochrome domains.

proteins are retained in non-photosynthetic bacteria but it has been suggested that the phytochrome-like sensor kinases in Agrobacterium may play a role in detecting depth in soil strata as a means of optimising interactions with roots [39]. Most of the bacterial phytochrome proteins have a PAS domain and a GAF domain at the N-terminus and a histidine kinase domain at the C-terminus (see Figure 4), though a phytochrome from Rhodobacter sphaeroides (UniProt:Q8VRN4; see Figure 4) has a more complex domain architecture [40]. The presence of two phytochromes in $P$. syringae, one of them with a unique architecture, may reflect the recruitment of phytochrome to a novel regulatory function unique to $P$. syringae. Protein PSPTO2652 from $P$. syringae is unique in that it has an additional C-terminal histidine kinase. Another unusual domain architecture is the PAS-GAF-PhytochromePAS organisation found in Xanthomonas proteins XAC4293 and XCC4154 (Figure 4), which, if shown to be functional, may represent a new phytochrome protein family. 


\section{Further analysis of novel Pseudomonas protein domain architectures}

The availability of multiple finished and unfinished Pseudomonas genomes allowed us to study in more detail the distribution, genomic context and properties of Pseudomonas gene products highlighted by this analysis. Closer examination of the genomic context of the $P$. syringae genes encoding proteins with unusual domain architectures showed that most were flanked on either or both sides by genes that have few or no orthologues in other Pseudomonas strains, suggesting that these novel genes have been recruited simultaneously with other genes, possibly of related function, or that they have recombined into the genome at hotspots for recombination and insertion of alien DNA.

To further address the hypothesis that at least some of these architectures have been acquired by horizontal gene transfer we examined the GC content and third position GC content of each of these genes, in comparison to the total genome ( 0.593 GC, 0.716 GC3). Sixteen of the genes deviated from the average GC3 content by more than 0.05. High GC3 content genes include pvsA, PSPTO4084, PSPTO2413 and $c f a 6$. Low GC3 content genes include hrpZ, PSPTO3210, glf, PSPTO4696, hopPtoS(1,2 \& 3), PSPTO2259, PSPTO0400, avrF and PSPTO1070. The GC content of flanking genes frequently reflected that of the novel gene, most strikingly for glf, PSPTO2441, PSPTO4696, hopPtoS(1,2 \&3), PSPTO4699, PSPTO 1070 \& PSPTO2632, which were each associated with low GC regions containing few ORFs with orthologues in other Pseudomonas genomes.

One other feature frequently associated with horizontally transferred genes is the presence of IS elements, tRNAs, plasmid and phage genes in flanking regions. PSPTO3229, PSPTO4569, PSPTO2312, PSPTO2829, PSPTO2310, Glf, PSPTO2441, PSPTO4696 and PSPTO2326 are all located in close proximity to IS elements and phage-like sequences, or in defined regions of the genome flanked by IS elements and phage-like sequences (see Figure 5).

Overall, this analysis suggests that a large number of the novel architectures present in $P$. syringae pathovar. tomato are uniquely associated with this species or pathovar of Pseudomonas, and that many of these genes have been acquired by horizontal gene transfer and are located in regions of the genome with a high potential for recombination and rearrangement.

\section{Conclusions}

Our initial observations, from the clustering of complete prokaryotic proteomes on the basis of domain content, motivated us to test whether any protein domains or domain architectures are specifically associated with a plant-associated lifefstyle. We identified nine protein domain families that are found in phylogenetically diverse plant-associated bacteria but not in non-plantassociated Bacteria (Table 1). Inevitably, there is an element of random chance in the species distribution of domain families; however, we observed that most of domains whose functions are at least partly known are implicated in the plant associated lifestyle. Therefore it seems possible that the two domains of unknown function (DUF811 and DUF1427) may also turn out to be significant for this lifestyle. Several domain families were also found only in plant pathogenic bacteria and in eukaryotes (Table 2). For example the RolB/RolC-like domain family is restricted to plant-associated bacteria and to plants of the genus Nicotiana, and is implicated in modulating auxin activity.

Having investigated patterns of presence or absence of domains within bacterial proteomes, we next identified which domains are most over-represented in the plantpathogenic Proteobacteria as compared with the frequency of occurrence in all the sequenced Proteobacteria (Table 3). Amongst the most over-represented domains was the guanylate cyclase domain. This was largely due to the large number of guanylate-cyclase-like proteins encoded by B. japonicum and S. meliloti. Although this approach may have revealed some potential leads for further investigation, it should be remembered that this analysis was rather crude and susceptible to the biased phylogenetic distribution of the organisms for which complete genome sequence data are currently available. However, detailed analysis of the frequency distributions of protein domain families in various organisms may yield rewards.

As well as the repertoire of domains, another important aspect of a proteome is the repertoire of domain architectures; that is the combinations of domains found within a single protein. Just as for the repertoire of domains, the species distribution of a domain architecture might be explained by chance. Nevertheless, the proteins listed in Table 4 may be a good starting point for further investigation of bacterium-plant interactions.

Many of these protein identified in this study have N-terminal predicted signal peptide motifs, suggesting that they are secreted. Further experiments are required to determine whether proteins of unknown function will also have a role in plant-specific functions. Many proteins involved in bacteria-plant interactions, such as TTSSsecreted effectors have subtle or conditional phenotypes, and would not be identified in conventional mutant-phenotype screens. Assays to detect subtle differences in growth in planta or in disease development are labour- 
PSPTO2310, 2312, 2326

PSPTO2441

PSPTO2829

PSPTO2898 (glf)

PSPTO3229

PSPTO4556, 4569

PSPTO4686 (cfa6), 4696
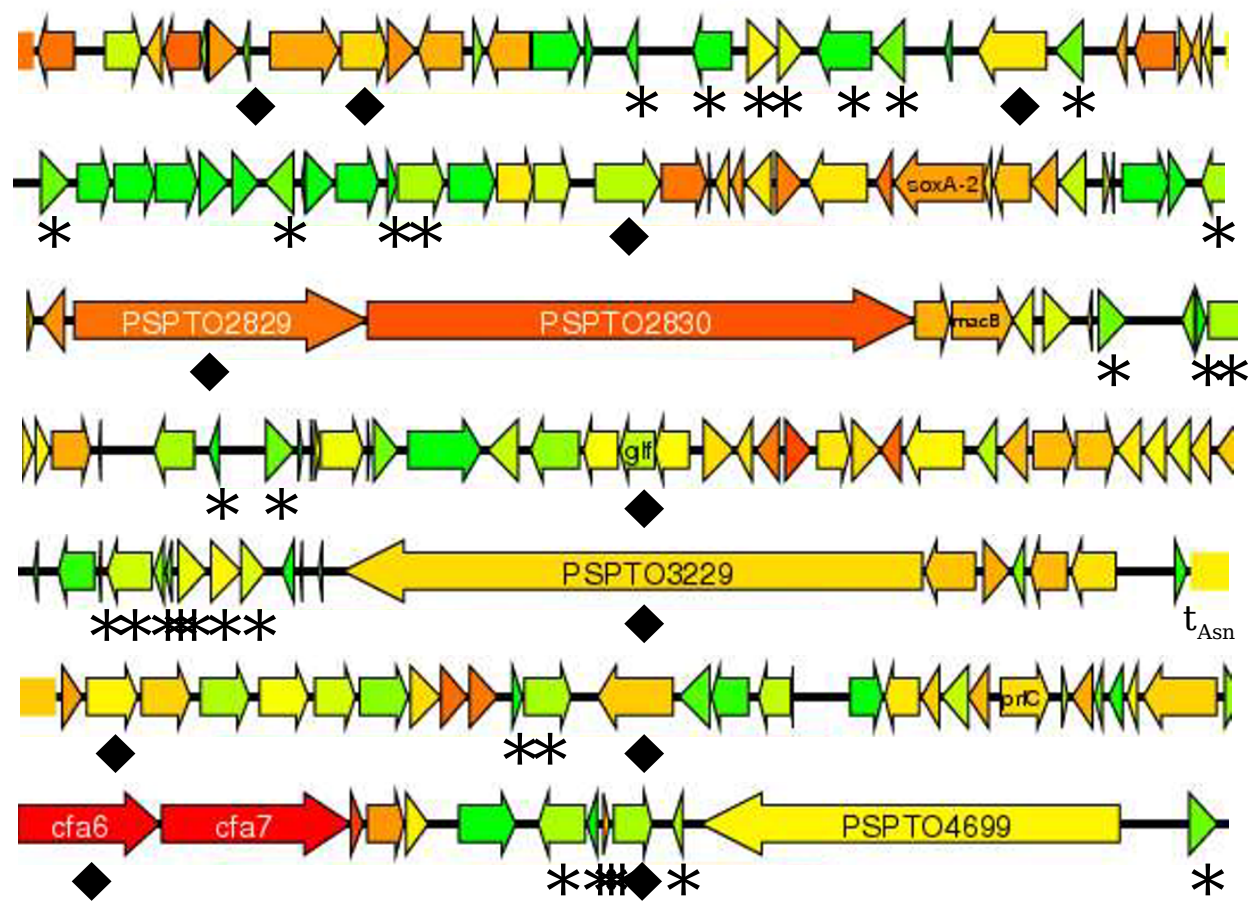

GC content

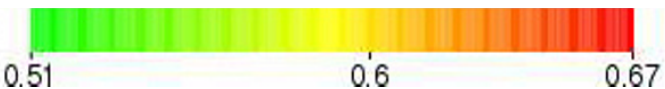

\section{Figure 5}

Genetic islands unique to Pseudomonas syringae. Genes encoding transposases are marked with an asterisk (*) and the asparaginyl tRNA gene is marked 'tAsn'. Black diamonds indicate genes encoding unique domain architectures [49].

intensive. Bioinformatic analyses such as this one represent useful and informative tools for reducing experimental search space, particularly when combined with other post-genomic techniques such as microarray analyses.

We found relatively little evidence of lateral dissemination of niche-specific novel architectures between phylogenetically distinct divisions in the Proteobacteria, with less than 20 phytobacteria-specific domain architectures present in two or more divisions of the Proteobacteria. We did identify a number of domain architectures and domains that were uniquely conserved in both plant-associated prokaryotes and eukaryotes. The methodology used in this study makes no prior assumptions about the nature or cause of "uniqueness". Unique architectures identified using this approach include rare domains, novel domain combinations and architectures that are truncated relative to the majority of similar proteins (which may represent deletions and loss of function mutations). Some proteins will inevitability be included or excluded because of the limitations of current domain prediction technology. However, in addition to identifying protein candidates for further investigation, this type of analysis can be used to challenge and improve current models for domain prediction and expose errors and limitations of genome sequence data and protein prediction. For example, consider a case in which a protein is identified as having the "unique" architecture B C C D. Additional examination of the protein may reveal that the protein has a similar sequence to proteins with the architecture $A \sim B \sim C \sim D$. The absence of the A domain may indicate a genuine alteration in structure and potentially in function, or a frameshift in the genome sequence data, or a functional "A" domain that fails to meet current predictive criteria. 
Each of these hypotheses can be tested by further research and experimentation, both in silico and in the lab.

Although our approaches to identifying candidate genes and proteins of significance to lifestyle have led to several potential leads and interesting hypotheses, there are some caveats. Firstly, evolution does not proceed exclusively through loss and gain of domains and domain shuffling; for example, protein innovation can also occur through mutation and divergence within domain families. Also, it is becoming increasingly apparent that an organism's physiology, behaviour and ecology depend as much on higher order 'systems level' phenomena as on the inventory of molecular components.

We chose to base our surveys of protein domains on the Pfam because this mature database is relatively comprehensive in its coverage (e.g. compared with SMART) and its data is of high quality. Furthermore, its data is distributed in a form that is ideally suited for constructing database queries such as those in this study. Another advantage is that in Pfam no two domains ever overlap in their coverage of a protein sequence, which significantly simplifies the analysis. However, it should be noted that Pfam is not absolutely infallible and some of its threshold values are rather stringent, leading to failure to identify some 'outlying' members of a domain family.

In summary, this study has described and applied a new approach for identifying architectural innovation and potentially important domains in proteins from genome sequence data. The data generated in this study have highlighted a large number of interesting and largely uncharacterised novel proteins and suggested new insights into the molecular basis of interactions between bacteria and their plant hosts, which will provide inspiration for future experimental research.

\section{Methods}

The Pfam relational database data files were downloaded from the Pfam website [46]. The census of domains and architectures were taken from Pfam release 16.0 (November 2004) using custom PERL scripts to wrap SQL queries against the Pfam relational database.

The complete bacterial genomes included in Pfam 16.0, and hence considered in this study, are listed in the supplementary data. We excluded from the analysis of domain architectures all protein sequences in UniProt [47] that are designated as fragments.

A file listing the presence or absence of each Pfam domain in each proteome can be found in the supplementary data. Each row in this file represented a vector used for the clustering of bacterial proteomes. Neighbour-joining was performed using PHYLIP [41]. Trees were visualised using ATV [51].

BLAST [42] searches were performed using the NCBI [48] and Expasy [49] web servers. Comparison between Pseudomonas genomes was aided by use of PseudoDB [50]. Transmembrane and signal peptide predictions were taken from Pfam, which in turn uses TMHMM [45] and SignalP [43]. It should be remembered that predictive methods often have difficulty distinguishing between signal peptides and N-terminal transmembrane helices [44].

\section{Authors' contributions}

DJS and GMP conceived the original study, carried out the bioinformatics analyses, and drafted the manuscript. JAD proposed extending the study to symbionts as well as pathogens. All the authors contributed to interpretation of the data and to writing the final manuscript.

\section{Additional material}

\section{Additional File 1}

This table lists the 459 domain architectures that are found in one or more plant-associated bacteria but are absent from other bacteria for which complete sequence data is available.

Click here for file

[http://www.biomedcentral.com/content/supplementary/1471-

2164-6-17-S1.pdf]

\section{Additional File 2}

Prokaryotic genomes included in Pfam16.0 (and hence in this study). Click here for file

[http://www.biomedcentral.com/content/supplementary/14712164-6-17-S2.pdf]

\section{Additional File 3}

"domains.tab.gz" Species distribution of each of the 3,774 Pfam domains. This tab-delimited file has been compressed using gzip.

Click here for file

[http://www.biomedcentral.com/content/supplementary/14712164-6-17-S3.GZ]

\section{Acknowledgements}

DJS is grateful to Lachlan Coin for early discussions about clustering of proteomes and over-representation of domains, which contributed to the conception of this work.

We thank Ray Dixon for helpful discussion. We are also indebted to the Pfam team for making their data readily available. Research at the Sainsbury Laboratory is funded by the Gatsby Charitable Foundation.

\section{References}

I. Wood DW, Setubal JC, Kaul R, Monks DE, Kitajima JP, Okura VK, Zhou Y, Chen L, Wood GE, Almeida NF Jr, Woo L, Chen Y, Paulsen IT, Eisen JA, Karp PD, Bovee D Sr, Chapman P, Clendenning J, Deatherage G, Gillet W, Grant C, Kutyavin T, Levy R, Li MJ, McClelland E, Palmieri A, Raymond C, Rouse G, Saenphimmachak C, Wu Z, Romero P, Gordon D, Zhang S, Yoo H, Tao Y, Biddle P, Jung M, Kre- 
span W, Perry M, Gordon-Kamm B, Liao L, Kim S, Hendrick C, Zhao ZY, Dolan M, Chumley F, Tingey SV, Tomb JF, Gordon MP, Olson MV, Nester EW: The genome of the natural genetic engineer Agrobacterium tumefaciens C58. Science 200I, 294:23I7-2323.

2. Goodner B, Hinkle G, Gattung S, Miller N, Blanchard M, Qurollo B, Goldman BS, Cao Y, Askenazi M, Halling C, Mullin L, Houmiel K, Gordon J, Vaudin M, lartchouk O, Epp A, Liu F, Wollam C, Allinger M, Doughty D, Scott C, Lappas C, Markelz B, Flanagan C, Crowell C, Gurson J, Lomo C, Sear C, Strub G, Cielo C, Slater S: Genome sequence of the plant pathogen and biotechnology agent Agrobacterium tumefaciens C58. Science 200I, 294:2323-2328.

3. Kaneko T, Nakamura Y, Sato S, Minamisawa K, Uchiumi T, Sasamoto S, Watanabe A, Idesawa K, Iriguchi M, Kawashima K, Kohara M, Matsumoto M, Shimpo S, Tsuruoka H, Wada T, Yamada M, Tabata S: Complete genomic sequence of nitrogen-fixing symbiotic bacterium Bradyrhizobium japonicum USDAII0. DNA Res 2002, 9:189-197.

4. Kaneko T, Nakamura Y, Sato S, Asamizu E, Kato T, Sasamoto $S$, Watanabe A, Idesawa K, Ishikawa A, Kawashima K, Kimura T, Kishida Y, Kiyokawa C, Kohara M, Matsumoto M, Matsuno A, Mochizuki Y, Nakayama S, Nakazaki N, Shimpo S, Sugimoto M, Takeuchi C, Yamada $M$, Tabata S: Complete genome structure of the nitrogen-fixing symbiotic bacterium Mesorhizobium loti. DNA Res 2000, 7:331-338.

5. Capela D, Barloy-Hubler F, Gouzy J, Bothe G, Ampe F, Batut J, Bois$\operatorname{tard}$ P, Becker A, Boutry M, Cadieu E, Dreano S, Gloux S, Godrie T, Goffeau A, Kahn D, Kiss E, Lelaure V, Masuy D, Pohl T, Portetelle D, Puhler A, Purnelle B, Ramsperger U, Renard C, Thebault P, Vandenbol M, Weidner S, Galibert F: Analysis of the chromosome sequence of the legume symbiont Sinorhizobium meliloti strain I02 I. Proc Natl Acad Sci USA 200I, 98:9877-9882.

6. Galibert F, Finan TM, Long SR, Puhler A, Abola P, Ampe F, BarloyHubler F, Barnett MJ, Becker A, Boistard P, Bothe G, Boutry M, Bowser L, Buhrmester J, Cadieu E, Capela D, Chain P, Cowie A, Davis RW, Dreano S, Federspiel NA, Fisher RF, Gloux S, Godrie T, Goffeau A, Golding B, Gouzy J, Gurjal M, Hernandez-Lucas I, Hong A, Huizar L, Hyman RW, Jones T, Kahn D, Kahn ML, Kalman S, Keating DH, Kiss E, Komp C, Lelaure V, Masuy D, Palm C, Peck MC, Pohl TM, Portetelle $D$, Purnelle $B$, Ramsperger $U$, Surzycki R, Thebault $P$, Vandenbol M, Vorholter FJ, Weidner S, Wells DH, Wong K, Yeh KC, Batut J: The composite genome of the legume symbiont Sinorhizobium meliloti. Science 200I, 293:668-672.

7. Nierman WC, Feldblyum TV, Laub MT, Paulsen IT, Nelson KE, Eisen JA, Heidelberg JF, Alley MR, Ohta N, Maddock JR, Potocka I, Nelson WC, Newton A, Stephens C, Phadke ND, Ely B, DeBoy RT, Dodson RJ, Durkin AS, Gwinn ML, Haft DH, Kolonay JF, Smit J, Craven MB, Khouri H, Shetty J, Berry K, Utterback T, Tran K, Wolf A, Vamathevan J, Ermolaeva M, White O, Salzberg SL, Venter JC, Shapiro L, Fraser CM, Eisen J: Complete genome sequence of Caulobacter crescentus. Proc Natl Acad Sci USA 200I, 98:4|36-4I4I.

8. Ogata H, Audic S, Renesto-Audiffren P, Fournier PE, Barbe $V$, Samson D, Roux V, Cossart P, Weissenbach J, Claverie JM, Raoult D: Mechanisms of evolution in Rickettsia conorii and R. prowazekii. Science 200I, 293:2093-2098.

9. Ogata $H$, Audic S, Barbe V, Artiguenave F, Fournier PE, Raoult D, Claverie JM: Selfish DNA in protein-coding genes of Rickettsia. Science 2000, 290:347-350.

10. Andersson SG, Zomorodipour A, Andersson JO, Sicheritz-Ponten T, Alsmark UC, Podowski RM, Naslund AK, Eriksson AS, Winkler HH, Kurland CG: The genome sequence of Rickettsia prowazekii and the origin of mitochondria. Nature 1998, 396:I33-I40.

II. Salanoubat M, Genin S, Artiguenave F, Gouzy J, Mangenot S, Arlat M, Billault A, Brottier P, Camus JC, Cattolico L, Chandler M, Choisne N, Claudel-Renard C, Cunnac S, Demange N, Gaspin C, Lavie M, Moisan A, Robert C, Saurin W, Schiex T, Siguier P, Thebault P, Whalen $M$, Wincker P, Levy M, Weissenbach J, Boucher CA: Genome sequence of the plant pathogen Ralstonia solanacearum. Nature 2002, 4I 5:497-502.

12. Tettelin H, Saunders NJ, Heidelberg J, Jeffries AC, Nelson KE, Eisen JA, Ketchum KA, Hood DW, Peden JF, Dodson RJ, Nelson WC, Gwinn ML, DeBoy R, Peterson JD, Hickey EK, Haft DH, Salzberg SL, White O, Fleischmann RD, Dougherty BA, Mason T, Ciecko A, Park sey DS, Blair E, Cittone H, Clark EB, Cotton MD, Utterback TR, Khouri H, Qin H, Vamathevan J, Gill J, Scarlato V, Masignani V, Pizza M, Grandi G, Sun L, Smith HO, Fraser CM, Moxon ER, Rappuoli R,
Venter JC: Complete genome sequence of Neisseria meningitidis serogroup B strain MC58. Science 2000, 287:1809-1815.

13. Parkhill J, Achtman M, James KD, Bentley SD, Churcher C, Klee SR, Morelli G, Basham D, Brown D, Chillingworth T, Davies RM, Davis P, Devlin K, Feltwell T, Hamlin N, Holroyd S, Jagels K, Leather S, Moule S, Mungall K, Quail MA, Rajandream MA, Rutherford KM, Simmonds M, Skelton J, Whitehead S, Spratt BG, Barrell BG: Complete DNA sequence of a serogroup A strain of Neisseria meningitidis Z249I. Nature 2000, 404:502-506.

14. Parkhill J, Sebaihia M, Preston A, Murphy LD, Thomson N, Harris DE, Holden MT, Churcher CM, Bentley SD, Mungall KL, Cerdeno-Tarraga AM, Temple L, James K, Harris B, Quail MA, Achtman M, Atkin R, Baker S, Basham D, Bason N, Cherevach I, Chillingworth T, Collins M, Cronin A, Davis P, Doggett J, Feltwell T, Goble A, Hamlin N, Hauser $\mathrm{H}$, Holroyd S, Jagels K, Leather S, Moule S, Norberczak H, O'Neil S, Ormond D, Price C, Rabbinowitsch E, Rutter S, Sanders M, Saunders D, Seeger K, Sharp S, Simmonds M, Skelton J, Squares R, Squares S, Stevens K, Unwin L, Whitehead S, Barrell BG, Maskell DJ: Comparative analysis of the genome sequences of Bordetella pertussis, Bordetella parapertussis and Bordetella bronchiseptica. Nat Genet 2003, 35:32-40.

15. Chain P, Lamerdin J, Larimer F, Regala W, Lao V, Land M, Hauser L, Hooper A, Klotz M, Norton J, Sayavedra-Soto L, Arciero D, Hommes $\mathrm{N}$, Whittaker M, Arp D: Complete genome sequence of the ammonia-oxidizing bacterium and obligate chemolithoautotroph Nitrosomonas europaea. Jacteriol 2003, 185:2759-2773.

16. Simpson AJ, Reinach FC, Arruda P, Abreu FA, Acencio M, Alvarenga R, Alves LM, Araya JE, Baia GS, Baptista CS, Barros MH, Bonaccorsi ED, Bordin S, Bove JM, Briones MR, Bueno MR, Camargo AA, Camargo LE, Carraro DM, Carrer H, Colauto NB, Colombo C, Costa FF, Costa MC, Costa-Neto CM, Coutinho LL, Cristofani M, DiasNeto E, Docena C, El-Dorry H, Facincani AP, Ferreira AJ, Ferreira VC, Ferro JA, Fraga JS, Franca SC, Franco MC, Frohme M, Furlan LR, Garnier M, Goldman GH, Goldman MH, Gomes SL, Gruber A, Ho PL, Hoheisel JD, Junqueira ML, Kemper EL, Kitajima JP, Krieger JE, Kuramae EE, Laigret F, Lambais MR, Leite LC, Lemos EG, Lemos MV, Lopes SA, Lopes CR, Machado JA, Machado MA, Madeira AM, Madeira HM, Marino CL, Marques MV, Martins EA, Martins EM, Matsukuma AY, Menck CF, Miracca EC, Miyaki CY, Monteriro-Vitorello CB, Moon DH, Nagai MA, Nascimento AL, Netto LE, Nhani A Jr, Nobrega FG, Nunes LR, Oliveira MA, de Oliveira MC, de Oliveira RC, Palmieri DA, Paris A, Peixoto BR, Pereira GA, Pereira HA Jr, Pesquero JB, Quaggio RB, Roberto PG, Rodrigues V, de M, Rosa AJ, de Rosa VE Jr, de Sa RG, Santelli RV, Sawasaki HE, da Silva AC, da Silva AM, da Silva FR, da Silva WA Ir, da Silveira JF, Silvestri ML, Siqueira WJ, de Souza AA, de Souza AP, Terenzi MF, Truffi D, Tsai SM, Tsuhako $M H$, Vallada $H$, Van Sluys MA, Verjovski-Almeida $S$, Vettore $A L$, Zago MA, Zatz M, Meidanis J, Setubal JC: The genome sequence of the plant pathogen Xylella fastidiosa. Nature 2000, 406: $151-157$

17. Van Sluys MA, de Oliveira MC, Monteiro-Vitorello CB, Miyaki CY, Furlan LR, Camargo LE, da Silva AC, Moon DH, Takita MA, Lemos EG, Machado MA, Ferro MI, da Silva FR, Goldman MH, Goldman GH, Lemos MV, El-Dorry H, Tsai SM, Carrer H, Carraro DM, de Oliveira RC, Nunes LR, Siqueira WJ, Coutinho LL, Kimura ET, Ferro ES, Harakava R, Kuramae EE, Marino CL, Giglioti E, Abreu IL, Alves LM, do Amaral AM, Baia GS, Blanco SR, Brito MS, Cannavan FS, Celestino AV, da Cunha AF, Fenille RC, Ferro JA, Formighieri EF, Kishi LT, Leoni SG, Oliveira AR, Rosa VE Jr, Sassaki FT, Sena JA, de Souza AA, Truffi D, Tsukumo F, Yanai GM, Zaros LG, Civerolo EL, Simpson AJ, Almeida NF Jr, Setubal JC, Kitajima JP: Comparative analyses of the complete genome sequences of Pierce's disease and citrus variegated chlorosis strains of Xylella fastidiosa. J Bacteriol 2003, 185:1018-1026.

18. da Silva AC, Ferro JA, Reinach FC, Farah CS, Furlan LR, Quaggio RB, Monteiro-Vitorello CB, Van Sluys MA, Almeida NF, Alves LM, do Amaral AM, Bertolini MC, Camargo LE, Camarotte G, Cannavan F, Cardozo J, Chambergo F, Ciapina LP, Cicarelli RM, Coutinho LL, Cursino-Santos JR, El-Dorry H, Faria JB, Ferreira AJ, Ferreira RC, Ferro MI, Formighieri EF, Franco MC, Greggio CC, Gruber A, Katsuyama AM, Kishi LT, Leite RP, Lemos EG, Lemos MV, Locali EC, Machado MA Madeira AM, Martinez-Rossi NM, Martins EC, Meidanis J. Menck CF, Miyaki CY, Moon DH, Moreira LM, Novo MT, Okura VK, Oliveira MC, Oliveira VR, Pereira HA, Rossi A, Sena JA, Silva C, de Souza RF, Spinola LA, Takita MA, Tamura RE, Teixeira EC, Tezza RI, Trindade dos Santos M, Truffi D, Tsai SM, White FF, Setubal JC, 
Kitajima JP: Comparison of the genomes of two Xanthomonas pathogens with differing host specificities. Nature 2002, 4I 7:459-463.

19. Buell CR, Joardar V, Lindeberg M, Selengut J, Paulsen IT, Gwinn ML, Dodson RJ, Deboy RT, Durkin AS, Kolonay JF, Madupu R, Daugherty S, Brinkac L, Beanan MJ, Haft DH, Nelson WC, Davidsen T, Zafar N, Zhou L, Liu J, Yuan Q, Khouri H, Fedorova N, Tran B, Russell D, Berry K, Utterback T, Van Aken SE, Feldblyum TV, D'Ascenzo M, Deng WL, Ramos AR, Alfano JR, Cartinhour S, Chatterjee AK, Delaney TP, Lazarowitz SG, Martin GB, Schneider DJ, Tang X, Bender CL, White $O$, Fraser CM, Collmer A: The complete genome sequence of the Arabidopsis and tomato pathogen Pseudomonas syringae pv. tomato DC3000. Proc Natl Acad Sci USA 2003, 100:10181-10186.

20. Stover CK, Pham XQ, Erwin AL, Mizoguchi SD, Warrener P, Hickey MJ, Brinkman FS, Hufnagle WO, Kowalik DJ, Lagrou M, Garber RL, Goltry L, Tolentino E, Westbrock-Wadman S, Yuan Y, Brody LL, Coulter SN, Folger KR, Kas A, Larbig K, Lim R, Smith K, Spencer D, Wong GK, Wu Z, Paulsen IT, Reizer J, Saier MH, Hancock RE, Lory $\mathrm{S}$, Olson MV: Complete genome sequence of Pseudomonas aeruginosa PAOI, an opportunistic pathogen. Nature 2000, 406:959-964.

21. Bell KS, Sebaihia M, Pritchard L, Holden MT, Hyman LJ, Holeva MC, Thomson NR, Bentley SD, Churcher LJ, Mungall K, Atkin R, Bason N, Brooks K, Chillingworth T, Clark K, Doggett J, Fraser A, Hance Z, Hauser H, Jagels K, Moule S, Norbertczak H, Ormond D, Price C, Quail MA, Sanders M, Walker D, Whitehead S, Salmond GP, Birch PR, Parkhill J, Toth IK: Genome sequence of the enterobacterial phytopathogen Erwinia carotovora subsp. atroseptica and characterization of virulence factors. Proc Natl Acad Sci USA 2004, I 0 I: I II05-III0.

22. Bateman A, Coin L, Durbin R, Finn RD, Hollich V, Griffiths-Jones S, Khanna A, Marshall M, Moxon S, Sonnhammer EL, Studholme DJ, Yeats C, Eddy SR: The Pfam protein families database. Nucleic Acids Res 2004, 32:DI38-DI4I

23. Letunic I, Copley RR, Schmidt S, Ciccarelli FD, Doerks T, Schultz J, Ponting CP, Bork P: SMART 4.0: towards genomic data integration. Nucleic Acids Res 2004, 32:DI42-DI44.

24. Krishnan HB: NolX of Sinorhizobium fredii USDA257, a type IIIsecreted protein involved in host range determination, lis localized in the infection threads of cowpea (Vigna unguiculata [L.] Walp) and soybean (Glycine max [L.] Merr.) nodules. J Bacteriol 2002, I 84:83 I-839.

25. Viprey V, Del Greco A, Golinowski W, Broughton WJ, Perret X: Symbiotic implications of type III protein secretion machinery in Rhizobium. Mol Microbiol I998, 28: I 38I-I 389.

26. Marie C, Deakin WJ, Viprey V, Kopcinska J, Golinowski W, Krishnan HB, Perret X, Broughton WJ: Characterization of Nops, nodulation outer proteins, secreted via the type III secretion system of NGR234. Mol Plant Microbe Interact 2003, I 6:743-75I.

27. Rossier O, Van den Ackerveken G, Bonas U: HrpB2 and HrpF from Xanthomonas are type III-secreted proteins and essential for pathogenicity and recognition by the host plant. Mol Microbiol 2000, 38:828-838.

28. Bai J, Choi SH, Ponciano G, Leung H, Leach JE: Xanthomonas oryzae pv. oryzae avirulence genes contribute differently and specifically to pathogen aggressiveness. Mol Plant Microbe Interact 2000, I3:1322-1329.

29. Estruch J], Schell J, Spena A: The protein encoded by the rolB plant oncogene hydrolyses indole glucosides. EMBO J 199I, I 0:3 | 25-3128

30. Estruch J], Chriqui D, Grossmann K, Schell J, Spena A: The plant oncogene rolC is responsible for the release of cytokinins from glucoside conjugates. EMBO J | 99|, I 0:2889-2895.

31. Young JM, Kuykendall LD, Martinez-Romero E, Kerr A, Sawada H: A revision of Rhizobium Frank with an emended description of the genus, and the inclusion of all species of Agrobacterium Conn 1942 and Allorhizobium undicola de Lajudie et al. I 998 as new combinations: $R$ hizobium radiobacter, $R$. rhizogenes, $R$. rubi, $\boldsymbol{R}$. undicola and $\boldsymbol{R}$. vitis. Int J Syst Evol Microbiol I889, 5 I:89-103.

32. Galperin MY, Nikolskaya AN, Koonin EV: Novel domains of the prokaryotic two-component signal transduction systems. FEMS Microbiol Lett 200I, 203: I I-2I.
33. Jenal U: Cyclic di-guanosine-monophosphate comes of age: a novel secondary messenger involved in modulating cell surface structures in bacteria? Curr Opin Microbiol 2004, 7: 185-191.

34. Paul R, Weiser S, Amiot NC, Chan C, Schirmer T, Giese B, Jenal U: Cell cycle-dependent dynamic localization of a bacterial response regulator with a novel di-guanylate cyclase output domain. Genes Dev 2004, I 8:7| 5-727.

35. Zhulin IB, Taylor BL, Dixon R: PAS domain S-boxes in Archaea, Bacteria and sensors for oxygen and redox. Trends Biochem Sci 1997, 22:331-333.

36. Sharrock RA, Quail PH: Novel phytochrome sequences in Arabidopsis thaliana : structure, evolution, and differential expression of a plant regulatory photoreceptor family. Genes Dev 1989, 3: I745-I757.

37. Jiang Z, Swem LR, Rushing BG, Devanathan S, Tollin G, Bauer CE: Bacterial photoreceptor with similarity to photoactive yellow protein and plant phytochromes. Science 1999, 285:406-409.

38. Karniol B, Vierstra RD: The pair of bacteriophytochromes from Agrobacterium tumefaciens are histidine kinases with opposing photobiological properties. Proc Natl Acad Sci USA 2003, 100:2807-2812.

39. Giraud E, Fardoux J, Fourrier N, Hannibal L, Genty B, Bouyer P, Dreyfus $B$, Vermeglio A: Bacteriophytochrome controls photosystem synthesis in anoxygenic bacteria. Nature 2002, 4 I 7:202-205.

40. Felsenstein J: PHYLIP - Phylogeny Inference Package (Version 3.2). Cladistics 1989, 5:164-166.

4I. Altschul SF, Gish W, Miller W, Myers EW, Lipman DJ: Basic local alignment search tool. J Mol Biol 1990, 2I 5:403-4I0.

42. Nielsen H, Brunak S, von Heijne G: Machine learning approaches for the prediction of signal peptides and other protein sorting signals. Protein Eng 1999, 12:3-9.

43. Kall L, Krogh A, Sonnhammer EL: A combined transmembrane topology and signal peptide prediction method. J Mol Biol 2004, 338:1027-1036.

44. Sonnhammer EL, von Heijne G, Krogh A: A hidden Markov mode for predicting transmembrane helices in protein sequences. Proc Int Conf Intell Syst Mol Biol 1998, 6: 175-82.

45. Pfam FTP site [ftp://ftp.sanger.ac.uk/pub/databases/Pfam/ database files/]

46. Apweiler R, Bairoch A, Wu CH, Barker WC, Boeckmann B, Ferro S Gasteiger E, Huang H, Lopez R, Magrane M, Martin MJ, Natale DA, O'Donovan C, Redaschi N, Yeh LS: UniProt: the Universal Protein knowledgebase. Nucleic Acids Res 2004, 32:DI I5-DI I 9.

47. NCBI BLAST [http://www.ncbi.nlm.nih.gov/BLAST/]

48. Expasy tools [http://ca.expasy.org/tools/\#similarity]

49. PseuodoDB [http://pseudo.bham.ac.uk/]

50. Zmasek CM, Eddy SR: ATV: display and manipulation of annotated phylogenetic trees. Bioinformatics 200I, I 7:383-384.

Publish with Bio Med Central and every scientist can read your work free of charge

"BioMed Central will be the most significant development for disseminating the results of biomedical research in our lifetime. "

Sir Paul Nurse, Cancer Research UK

Your research papers will be:

- available free of charge to the entire biomedical community

- peer reviewed and published immediately upon acceptance

- cited in PubMed and archived on PubMed Central

- yours - you keep the copyright
BioMedcentral 